\title{
Complete Appendiceal Intussusception induced by Primary Adenocarcinoma of the Vermiform Appendix: A Rare Case Report and Review of the Relevant Literature
}

\author{
${ }^{1}$ Samer Ebaid, ${ }^{2}$ Saptarshi Biswas, ${ }^{3}$ Prem Patel
}

\begin{abstract}
Appendicular intussusception is a rare entity. Although first reported in 1858 there are only 250 cases reported since. In a large autopsy series the incidence rate of only $0.01 \%$ was documented. The exact pathophysiology is unclear but several etiologies have been documented. Primary adenocarcinoma of the appendix is extremely uncommon, which in most cases arises from a pre-existing adenoma. The incidence according to a reported study was documented as $0.08 \%$.

We report an uncommon case of a young female who presented with a 2-day history of abdominal pain with nausea and vomiting. Computed tomography scan suggested of ileocolic intussusception. Diagnostic laparoscopy was performed followed by open laparotomy. An appendicular tumor confirmed as adenocarcinoma of the appendix on frozen section was noted to be the cause of the intussusception. A right hemicolectomy was performed.

We discuss the different anatomical and pathological factors causing appendicular intussusception with special emphasis on primary adenocarcinoma of the appendix, clinical features, classifications, preoperative diagnoses and treatment options of this rare disease entity along with review of relevant literature.
\end{abstract}

Keywords: Adult, Appendiceal intussusception, Adenocarcinoma.

How to cite this article: Ebaid S, Biswas S, Patel P. Complete Appendiceal Intussusception induced by Primary Adenocarcinoma of the Vermiform Appendix: A Rare Case Report and Review of the Relevant Literature. Panam J Trauma Crit Care Emerg Surg 2015;4(1):36-38.

Source of support: Nil

Conflict of interest: None

\footnotetext{
${ }^{1}$ Resident, ${ }^{2,3}$ Attending Surgeon

${ }^{1}$ Department of General Surgery, Brookdale University Hospital Brooklyn, New York, USA

${ }^{2}$ Department of Trauma and Acute Care Surgery, Allegheny Health Network, PA, United States

${ }^{3}$ Department of Surgery, Brookdale University Hospital, New York, United States
}

Corresponding Author: Saptarshi Biswas, Attending Surgeon, Department of Trauma and Acute Care Surgery Allegheny Health Network, PA, United States, Phone: 7182406387, e-mail: saptarshibiswas@comcast.net

\section{RESUMEN}

La intususcepción apendicular es una entidad rara. Aunque su primera vez reportada fue en 1858, sólo existen 250 casos registrados desde entonces. En una gran serie de autopsias la tasa de incidencia documentada fue sólo del 0,01\%. La fisiopatología exacta no está clara, pero varias etiologías han sido documentadas. El adenocarcinoma primario del apéndice es extremadamente raro, ya que en la mayoría de los casos surge de un adenoma pre-existente. La incidencia de acuerdo a un estudio publicado fue de $0,08 \%$. Presentamos un caso poco frecuente de una mujer joven que se presentó con historia de 2 días de dolor abdominal con náuseas y vómito. La imagen por tomografía computarizada sugirió una intususcepción ileocólica. Se realizó laparoscopia diagnóstica seguida de laparotomía abierta. Un tumor apendicular confirmado como adenocarcinoma del apéndice sobre sección congelada, fue observado como la causa de la intususcepción. Se realizó hemicolectomía derecha. Discutimos los diferentes factores anatómicos y patológicos causantes de la intususcepción apendicular, con énfasis en adenocarcinoma primario de la apéndice, sus características clínicas, clasificaciones, diagnósticos preoperatorio y opciones de tratamiento de esta enfermedad rara junto con la revisión de literatura relevante.

Palabras claves: Adulto, Intususcepción apendicular, Adenocarcinoma.

\section{INTRODUCTION}

Intussusception of the appendix is a rare condition. ${ }^{1,2}$ Primary adenocarcinoma of the appendix is also rare and arises from a preexisting adenoma in most cases. ${ }^{3}$ The first case of appendiceal intussusception (AI) was reported in 1858 by McKidd. ${ }^{4}$ Hemakini et al in 2010 reported 250 documented cases. ${ }^{5}$ In a study of 71,000 human appendices done by Collins, the incidence of intussusception was only $0.01 \% .{ }^{6}$ Appendiceal intussusception is often caused by anatomical pathological factor and is rarely diagnosed prior to surgery.

We report a unique case of intussusception of the appendix caused by primary appendiceal adenocarcinoma and discuss the presentation, etiology, classifications and operative management of such a condition.

\section{CASE REPORT}

A 35-year-old African-American female with medical history of hypertension was admitted to the hospital with right-sided abdominal pain of 2 days duration

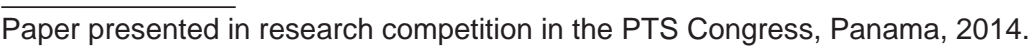


associated with nausea, vomiting and diarrhea. The pain was described as squeezing in nature, 9/10 in severity, of intermittent course and was exacerbated by oral intake.

History was consistent with three cesarean sections. On admission, the patient was afebrile with stable vitals. Clinical examination revealed soft, nondistended abdomen with tenderness in the right lower quadrant without peritoneal signs.

Computed tomography (CT) scan of the abdomen and pelvis with oral and intravenous contrast were done the report of which were suggestive of an ileocolic intussusception (Figs 1 and 2).

\section{Operative Findings}

A midline incision starting above the umbilicus going down to the pubic symphysis was made. A tubular mass was felt moving side by side inside the right colon. The ileum was found to be grossly normal. No appendix could be found. The cecum was mobilized incising along the line of Toldt, and following that the cecum was opened

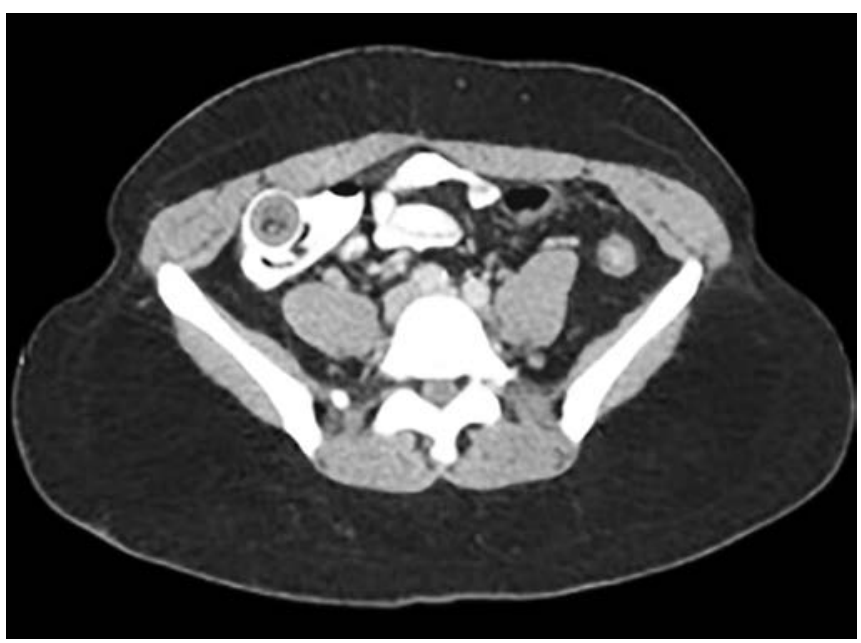

Fig. 1: Computed tomography scan showing right lower quadrant ileocolic intussusception

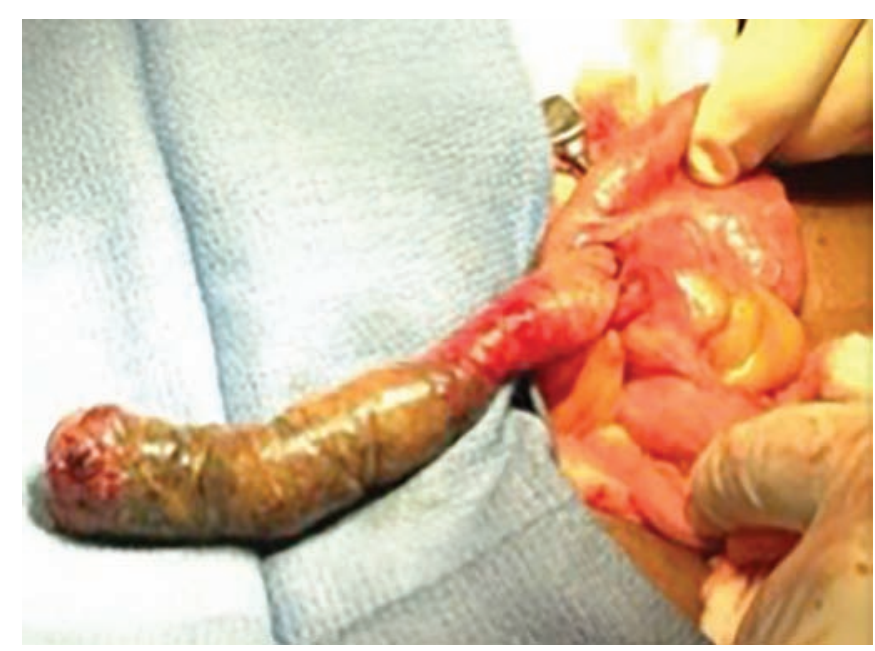

Fig. 3: Intraoperative image showing gangrenous appendix up to the base very close to the base around the area of the base of the appendix, and it was noticed that there was a tubular structure intussuscepted into the lumen of the cecum, This was an appendicular intussusception with a totally gangrenous appendix (Figs 3 and 4).

A right hemicolectomy followed by a side-to-side ileocolic anastomosis was done using a GIA-80 stapler. The patient tolerated the procedure well.

\section{PATHOLOGY}

A specimen is showing a gangrenous vermiform appendix measuring $9.5 \times 2 \times 1.5 \mathrm{~cm}$ with foci with adenocarcinoma with negative margins. Eight lymph nodes were negative for metastases. Right colon showed edema and acute inflammation of the submucosa and superficial muscular is propria (Fig. 5).

\section{DISCUSSION}

Colonic intussusception is the invagination of one part of the colon into the lumen of the distal part of the colon

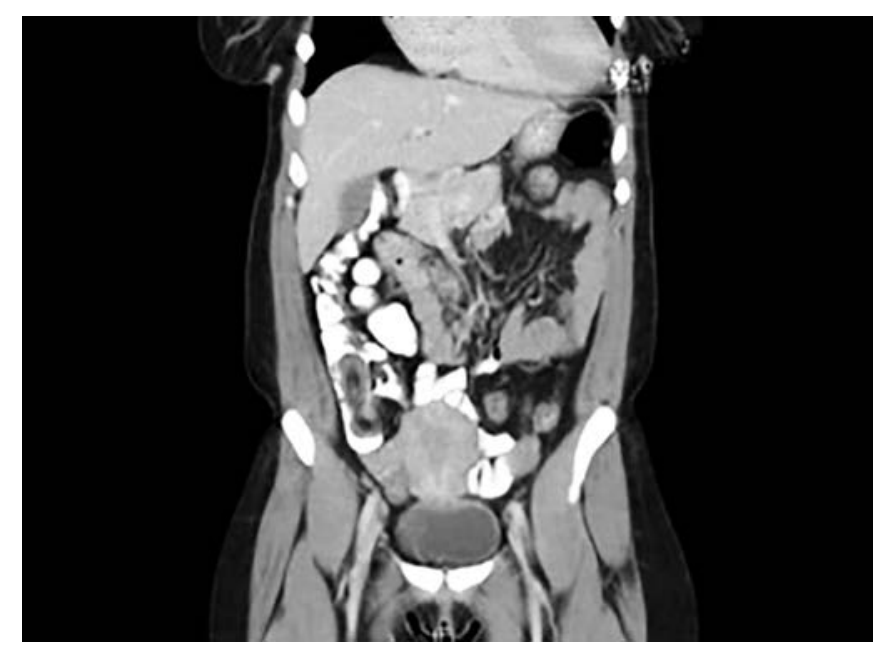

Fig. 2: lleo colic intussusception

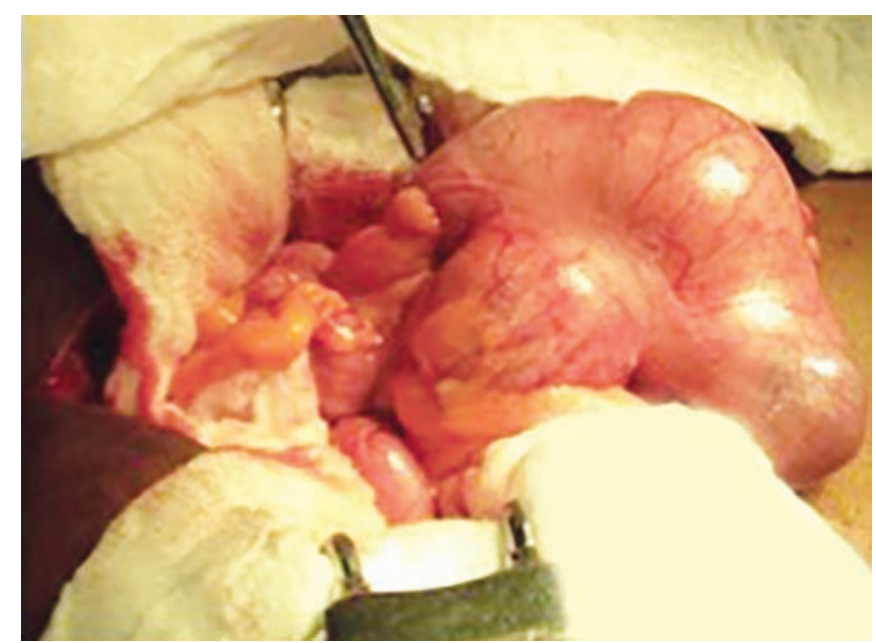

Fig. 4: Intraoperative image showing cecum containing the intussuscepted appendix 


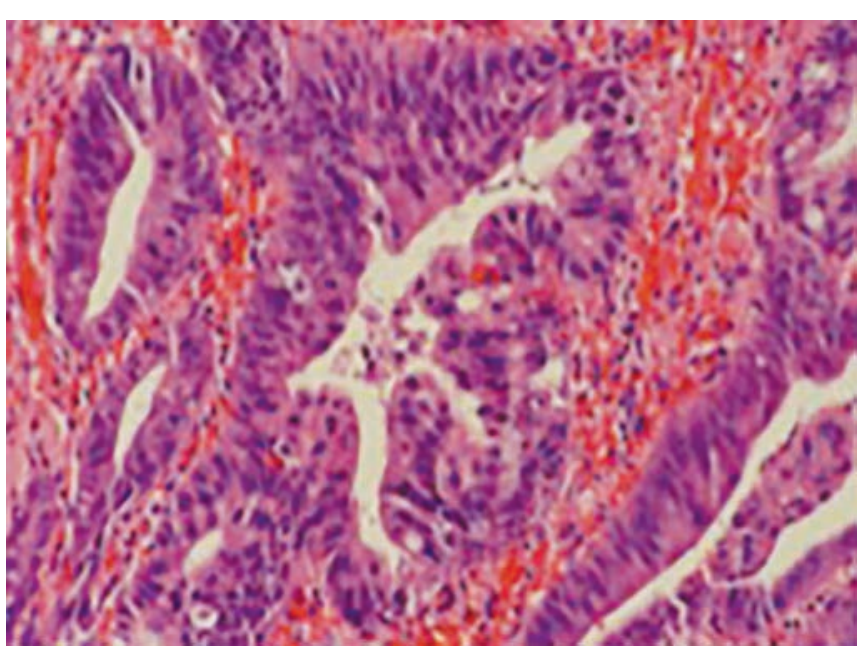

Fig. 5: Microscopic image of gangrenous appendix with foci of adenocarcinoma

and could be colocolic or ileocolic. ${ }^{1}$ Intussusception of the appendix is a rare surgical condition. The incidence of intussusception of the appendix was reported to be as low as $0.01 \%$ in a large series. It is seldom diagnosed preoperatively due to the nonspecific nature of the presenting symptoms. Patients can be asymptomatic or can present with signs of acute appendicitis $(25 \%)$ chronic abdominal colics $(50 \%)$ or bleeding per rectum..$^{6-8}$

The etiology of AI is either due to anatomical or pathological abnormalities. Anatomical abnormalities include fetal-type cecum and a thin mobile appendix with a wide lumen. Pathological abnormalities commonly include endometrial implants, fecolith, worms or tumors. ${ }^{9}$

Langsam classified AI into four types based on their anatomy. In type 1, the tip of the appendix is the intussuceptum and the proximal appendix is the intussuscipiens. In type 2, the base of the appendix is the intussusceptum and the cecum is the intussuscipiens. In type 3 , the proximal appendix is received into the distal portion. Type 4 is complete inversion and so called 'inside out' appendix with accompanying ileocecal intussusception. Type 1 or type 2 can progress to type 4 , with the appendix serving as the lead point.

Tumors of the appendix are rare and mostly benign. The incidence of appendiceal adenocarcinoma is only $0.08 \%$ with only two reported cases associated with intussusception. Primary appendiceal adenocarcinoma are classified into two pathological types either cystic adenocarcinoma or colonic type adenocarcinoma. Cystic adenocarcinoma at the appendix is relatively more common and mostly arises from a precursor cystadenoma. It is a mucus-producing tumor and if ruptured can result in pseudomyxoma peritonei. Colonic type adenocarcinoma, on the contrary, is less common and arises from a tubular or tubulovillous adenoma. It can be polypoid or ulcerative in appearance and could spreads via lymphatic system or blood stream and usually have a worse prognosis.

Preoperative diagnosis is often difficult and almost always diagnosed incidentally during the laparotomy. Double contrast barium enema or colonoscopy can be used for the diagnosis of AI. 'Coiled spring' sign in barium studies and 'target-like' appearance or 'concentric ring' sign on ultrasound are suggestive of AI. Endoscopic finding of AI consists of inverted appendices often simulate cecal or ascending colon polyp. ${ }^{10}$ High resolution CT is often diagnostic for $\mathrm{AI}$ and for identifying the nature of the leading point. ${ }^{11}$

Surgery is the mainstay of treatment. A right hemicolectomy with lymph node dissection should be performed when carcinoma is diagnosed and the tumor is more than $2 \mathrm{~cm}$ in diameter. Though increasingly used, indications for the laparoscopic approach to the resection of appendiceal tumors have not yet been fully established.

\section{REFERENCES}

1. Ben-Aaron U, Shperber J, Halevy A, Negri M, Bogokovski H, Orda R. Primary adenocarcinoma of the appendix: report of five cases and review of the literature. J Surg Oncol 1987 Oct; 36(2):113-115.

2. Deans GT, Spence RA. Neoplastic lesions of the appendix. Br J Surg 1995 Mar;82(3):299-306.

3. Chick-Kwin Tang. Disorders of the vermiform appendix. In: Ming and Goldman, Pathology of the Gastrointestinal Tract. Philadelphia: WB Saunders; 1992. p. 878.

4. McKidd J. Case of invagination of cecum and appendix. Edinburgh Med J 1858;4:793.

5. Hemakini, Kaur H, Khadilkar U, Rau AR, Rao HT, Tantry BV. 'The inside out appendix' report of two cases. Trop Gastroenterol 2010 Jan-Mar;31(1):55-56.

6. Collins DC. 71,000 Human appendix specimens: a final report, summarizing forty years' study. Am J Proctol 1963 Dec;14:265-281.

7. Howard RJ, Ellis CMC, Delaney JP. Intussuception of the appendix simulating carcinoma of the cecum. Arch Surg 1970;101(4):520-522.

8. Sadahiro S, Ohmura T, Yamada Y, Saito T, Akatsuka S. A case of cecocolic intussusception with complete invagination and intussusception of the appendix with villous adenoma. Dis Col Rectum 1991;34(1):85-88.

9. Langsam LB, Raj PK, Galang CF. Intussusception of the appendix. Dis Colon Rectum 1984;27(6):387-392.

10. Jevon GP, Daya D, Qizilbash AH. Intussusception of the appendix. Arch Pathol Lab Med 1992;116(9):960-964.

11. Takehara Y, Takahashi M, Isoda H, Kaneko M, Mochizuki K, Yuasa H, Aiba K, Kawaguchi K. Adult intussusception with an appendiceal mucocele diagnosed by $\mathrm{CT}$ and ultrasonography. Radiat Med 1989 May-Jun;7(3):139-142. 